(2) Open Access Full Text Article

\title{
Impact of conjunctival autograft on pterygium treatment: evaluation of related symptoms and patients' satisfaction after surgery
}

This article was published in the following Dove Press journal:

Clinical Ophthalmology

\author{
Ana Cláudia Viana \\ Wanzeler' \\ Bruna Duarte ${ }^{1,2}$ \\ Vitor Duarte Moron de \\ Andrade ${ }^{2}$ \\ Monica Alves' \\ 'Department of Ophthalmology, \\ University of Campinas, Campinas, SP, \\ Brazil; ${ }^{2}$ Pontific Catholic University of \\ Campinas, Campinas, SP, Brazil
}

Correspondence: Ana Cláudia Viana Wanzeler

University of Campinas, Rua Vital Brasil, Cidade Universitária, Campinas, I3083888, SP, Brazil

Email anaclaudiavw@yahoo.com.br
Purpose: Pterygium is a fibrovascular condition of the ocular surface that can cause a broad range of irritative and visual symptoms. Controversy exists regarding pterygium mechanisms, management, surgical techniques, adjuvant approaches and impact on patients' quality of life. We performed a retrospective survey focused on the impact of pterygium-related symptoms before surgery and patients' satisfaction after excision surgery followed by conjunctival autograft transplantation with fibrin glue, based on patients' subjective reporting.

Methods: All patients underwent surgery consisting of the extensive removal of the pterygium fibrovascular tissue, followed by autologous conjunctival graft fixed with fibrin glue to cover the bare scleral area. A total of 500 patients were contacted by phone call and invited to participate in the study answering a brief two-question survey. First, to grade overall intensity of symptoms related to pterygium before surgical intervention, such as pain, irritation, tearing, red eye, photophobia, burning and foreign body sensation, using a scale from 0 to 10 ( 0 asymptomatic and 10 very severe symptoms). Results were categorized as mild (0-3), moderate (4-7) and severe (8-10). Then, patients were asked about their satisfaction with the surgery outcome, also using a scale from 0 to 10 (ranging from dissatisfied to fully satisfied).

Results: Patients' mean age was $41.5 \pm 12.31$ ( $\min 18 / \mathrm{max} 83$ ) years old and the mean of days after surgery was $1,493 \pm 552.7$ ( $\min 711 / \max 2,702)$. Symptoms were referred to as severe (70.2\%), moderate $(25.2 \%)$ and mild (4.6\%). After surgery, most patients were fully satisfied and the mean grade was $9.6 ; 1 \%(0-3), 2.4 \%(4-7)$ and $96.6 \%(8-10)$. Women presented a higher score of symptoms compared to men $(P<0.01)$ but similar satisfaction rates.

Conclusions: The present study shows that pterygium greatly impacts on patients' quality of life and that excision surgery using conjunctival autograft transplantation and fibrin glue improved symptoms with high rates of satisfaction.

Keywords: pterygium, autologous conjunctival graft, surgery, symptoms, quality of life, fibrin glue

\section{Introduction}

Pterygium is an inflammatory and degenerative disease of the ocular surface characterized by conjunctiva growth over the cornea forming a triangular-shaped fibrovascular tissue. It can cause symptoms such as ocular discomfort, cosmetic problems, irregular astigmatism and even impacts on visual acuity. Despite the consistent evidence correlating pterygium development to high ultraviolet exposure, genetic factors may also be involved. ${ }^{1}$ Age, sex, smoking, race and geographical latitude were also reported in several studies. ${ }^{2}$ Pterygium formation can be characterized by cell proliferation, inflammatory processes, angiogenesis and extracellular matrix degradation. ${ }^{1}$ 
The prevalence of pterygium varies worldwide. Countries located in tropical regions may show prevalence rates of $22 \%$, while countries outside these areas only $2 \%{ }^{3}$ Overall prevalence was estimated at $10.2 \%{ }^{4}$ Data on the prevalence of pterygia in Brazil are still very scarce.

Most often, symptoms are reported as foreign body sensation, ocular burning, tearing and red eye which can be deeply uncomfortable as well as cosmetically disturbing. Diagnosis is made through slit lamp exam observing pterigyum features as involutive or fleshy, primary or recurrent and classification according to lesion size, as: grade 1 when the lesion reaches the limbus, grade 2 when it covers the cornea by about $2 \mathrm{~mm}$, grade 3 when it reaches the pupil margin and grade 4 when it extends over the pupil. Consensus indicates surgical treatment of the pterygium when symptoms justify such a procedure, in cases where the lesion extends to the central part of the cornea, obstructing the visual axis, or when it brings cosmetic inconvenience. ${ }^{5}$ Recurrence rates are higher among young patients and have been associated with family history and surgical procedures. ${ }^{6}$

Several techniques have been described for surgical treatment of pterygium such as avulsion, deep dissection, superficial keratectomy, which can be associated or not with conjunctival flap, autologous conjunctival transplantation or amniotic membrane. ${ }^{7-11}$ Graft fixation also varies with the use of surgical threads, fibrin glue or even autologous blood. Some techniques such as beta therapy and naked sclera have been considered outdated due to the high risk of complications and recurrence. Chemical agents are described for removal of the epithelium, such as absolute alcohol diluted to $20 \%$, and antimetabolites (Mitomycin C and 5-fluorouracil) have been used as adjuvants to decrease recurrence. ${ }^{7,8}$ More recently, anti-vascular endothelial growth-factor has also been used as an adjuvant for the purpose of decreasing angiogenesis, and hence recurrence rates. ${ }^{12}$ Nevertheless, surgical treatment is indicated when satisfactory clinical control is not achieved, but still remains a great challenge.

In Brazil, there is a lack of population-based studies that present a more complete characterization of the individuals with pterygium, as well as the analysis of risk and aggravating factors, and repercussions on the quality of life of the patients.

This study aims to evaluate the impact of pterygium-related symptoms prior to surgery and patients' satisfaction after excision associated with the use of a conjunctival autograft transplant with fibrin glue. Our purpose was to evaluate those endpoints based only on patients' subjective reports.

\section{Methods}

The study was carried out with the approval of the Institutional Research Ethics Committee Board (University of Campinas - UNICAMP) and was conducted in accordance with the tenets of the Declaration of Helsinki and current legislation on clinical research. Informed verbal consent, approved by the Institutional Research Ethics Committee Board, was obtained from all subjects after a brief introductory explanation about the study, during a phone call placed by the interviewers. For those who agreed to participate, the questionnaire was presented and the answers were collected.

This retrospective study was designed enrolling a total of 500 patients, who were contacted by phone call for a simple two-question survey regarding, (1) the intensity of pterygium-related symptoms, and (2) their satisfaction after surgical treatment.

The cohort of participants consisted of patients who had undergone pterygium surgery in period varying from 2 to 7 years. The surgical procedure was performed in the same fashion by the same surgeon (M Alves) and consisted of extensive removal of the pterygium fibrovascular tissue, followed by autologous conjunctival graft fixed with fibrin glue to cover the bare scleral area. Figure 1 shows some
A

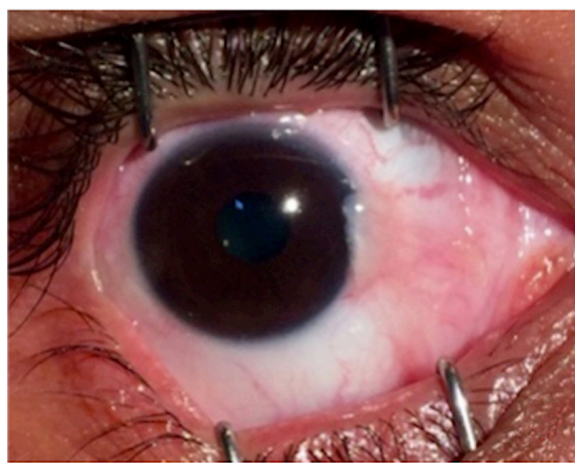

B

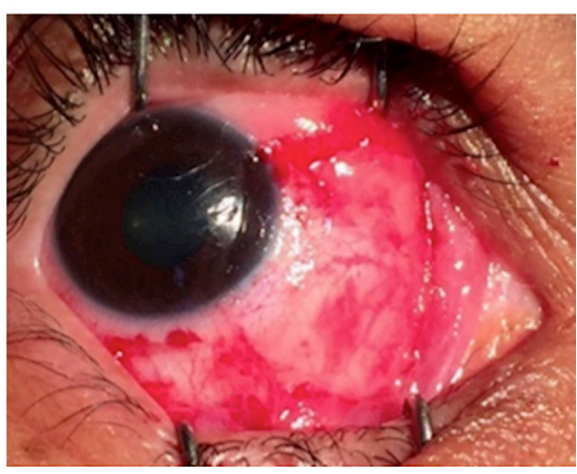

Figure I Illustrative example of surgical technique: pterygium removal followed by conjunctival autograft with fibrin glue fixation (A) before surgery, and (B) final appearance. 


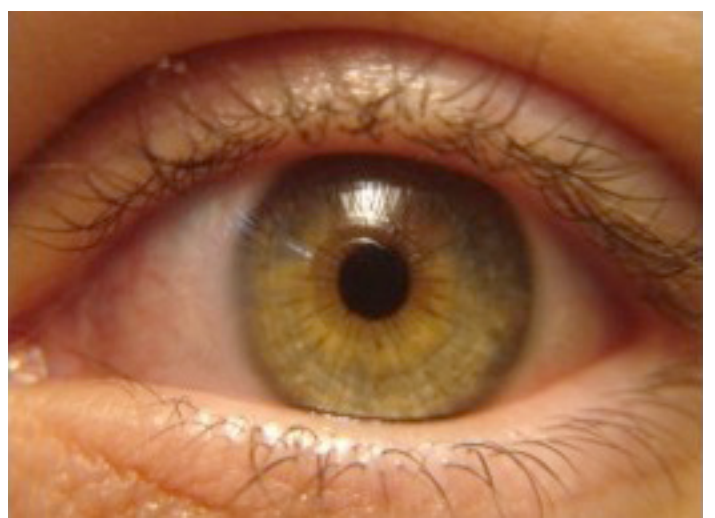

Figure 2 Illustrative example of final ocular surface appearance 3 months after pterigyum removal and autologous conjuntival graft. No recurrence.

examples of the surgical technique and Figure 2 illustrates some of the latest results.

All contact phone calls followed the same process and were performed by one of the co-authors (BDM Andrade or VDM Andrade). After a brief introductory presentation, the researcher explained the purpose of the study and, with verbal informed consent, applied the questionnaire. First, the patients were asked to grade overall symptoms related to pterygium prior to surgical intervention, such as pain, irritation, tearing, red eye, photophobia, burning and body sensation, using a scale from 0 to 10 (0 asymptomatic and 10 very severe symptoms). Result scores were classified as mild (0-3), moderate (4-7) and severe (8-10). Then, the patients were asked about their satisfaction concerning surgery outcome, also using a scale from 0 to 10 (ranging from dissatisfied to fully satisfied).

Descriptive statistics for continuous data were reported as mean $\pm \mathrm{SD}$ and continuous variables were compared using the nonpaired $t$-test or Kruskal-Wallis nonparametric test (with Dunn's post hoc test) when two or more groups were analyzed, respectively. Differences were considered to be significant when $P<0.05$. All statistical analyses were performed using SPSS v.21.0 software (SPSS Incorporation, Chicago, IL, USA).

\section{Results}

Patients' mean age was 41.51 ( $\min 18 / \max 83$ ) years old and the mean of days after surgery was 1,493 ( $\min 711 / \max$ $2,702)$ days. Symptoms were referred to as severe (70.2\%), moderate $(25.2 \%)$ and mild (4.6\%). After surgery, most patients were fully satisfied and the mean grade was 9.56 ; 1\% (0-3), 2.4\% (4-7) and 96.6\% (8-10) (Figure 3).

According to preoperative symptoms mean ages were

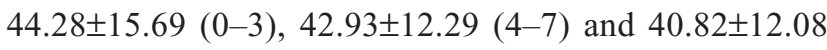
(8-10) $(P<0.05)$. Thus, younger patients tend to present with more inflamed pterygia and more intense symptoms.

However, the mean satisfaction rates related to the symp-

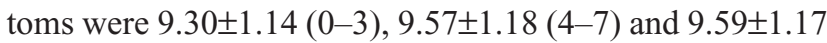
$(8-10)$, with no statistical significance $(P=0.32)$. When comparing satisfaction according to each age group, the mean satisfaction rates were 9.66 $\pm 1.05(18-40), 9.53 \pm 1.03(41-60)$ and 9.39 $\pm 1.14(61-83)(P=0.18)$. Table 1 shows patients' satisfaction rates according to preoperative symptom grades and Table 2 shows the preoperative symptoms and satisfaction evaluated according to age group.

Regarding differences according to sex, women presented higher levels of symptoms scores compared to men, regardless of similar scores on postoperative satisfaction (Table 3 and Figure 4).

\section{Discussion}

Primary pterygium surgery aims to improve symptomatology and reconstruct ocular surface regularity, as well as to preserve visual acuity and avoid recurrence. There is an
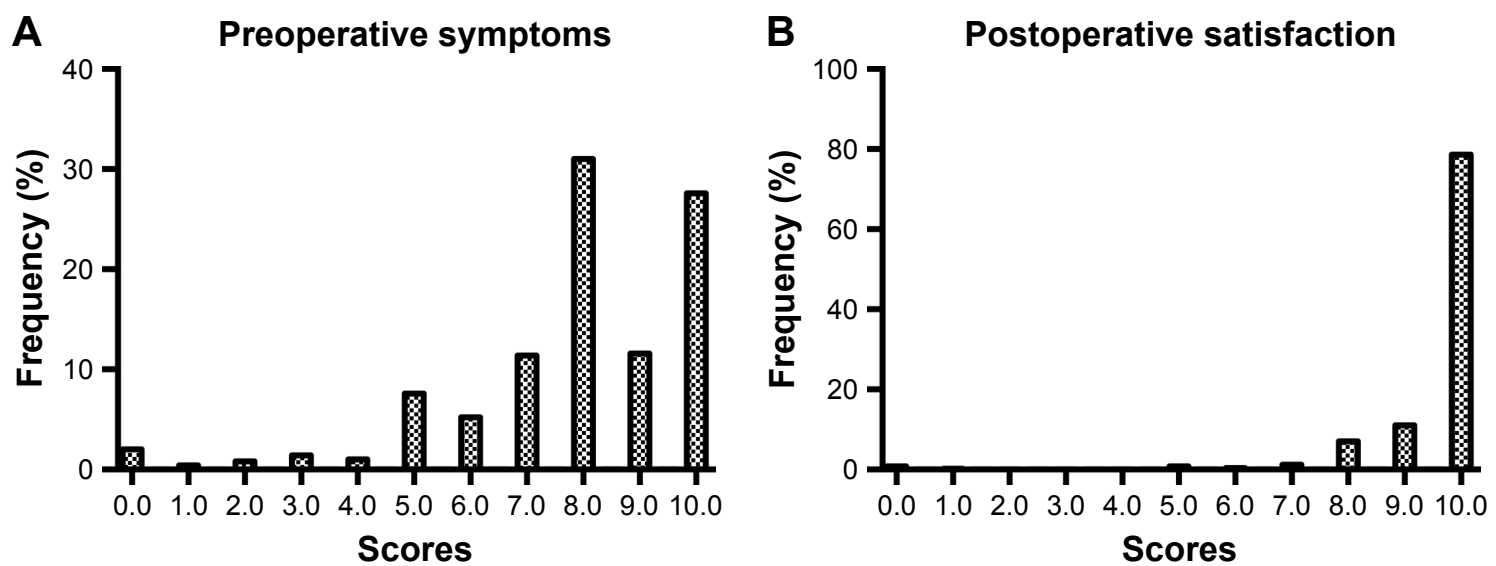

Figure 3 Overall scores for preoperative symptoms (A) and postoperative satisfaction (B). 
Table I Patients' satisfaction according to preoperative symptoms score

\begin{tabular}{llll}
\hline $\begin{array}{l}\text { Symptoms } \\
\text { score }\end{array}$ & $\begin{array}{l}\text { Number } \\
\text { of patients } \\
(\mathbf{N}=\mathbf{5 0 0 )}\end{array}$ & $\begin{array}{l}\text { Satisfaction } \\
\text { scores }\end{array}$ & $\begin{array}{l}\text { Age } \\
\text { (years) }\end{array}$ \\
\hline $0-3$ & 23 & $9.30 \pm 1.14$ & $44.28 \pm 15.69$ \\
$4-7$ & 126 & $9.57 \pm 1.18$ & $42.93 \pm 12.29$ \\
$8-10$ & 351 & $9.59 \pm 1.17$ & $40.82 \pm 12.08$ \\
\hline
\end{tabular}

indication for surgical treatment when symptoms justify the procedure, such as where patients show no improvement with clinical treatment, have very important complaints or even have vision impairment due to corneal irregularities or obstruction of the visual axis by the pterygium..$^{1,5,6}$

Historically, several surgical techniques have been described for the pterygium excision, usually chosen according to the characteristics of the lesion and the ability and personal preferences of the surgeon. The conjunctival transplantation presents a lower recurrence rate, varying from 4.8 to $12.3 \%$. The use of biological glue greatly reduces surgical time and postoperative inflammation, shortening the need for corticosteroid therapy and providing greater comfort for the patient. Some authors even suggest that recurrence rates are smaller when it is not applied at the suture site, but the information remains controversial. ${ }^{9-11}$

The mean age of patients was evaluated and compared to the intensity of the symptoms, showing that relatively younger pterygium carriers have more intense symptoms, probably due to the presence of more inflamed and active pterygia.

Patients older than 60 years had lower satisfaction rates despite still having a high score, ranging from 9.66 to 9.39 . This may be related to the fact that they report fewer preoperative symptoms, thus presenting less postoperative satisfaction. Differently, younger patients were the most symptomatic before the surgery and the most satisfied after the procedure.

Concerning preoperative symptoms, the majority of participants classified the symptoms as severe, reinforcing the fact that those patients were candidates for the surgical procedure.

Table 2 Preoperative symptoms and postoperative satisfaction according to age

\begin{tabular}{llll}
\hline $\begin{array}{l}\text { Age } \\
\text { (years) }\end{array}$ & $\begin{array}{l}\text { Number } \\
\text { of patients } \\
\mathbf{( N = 5 0 0 )}\end{array}$ & $\begin{array}{l}\text { Symptoms } \\
\text { scores }\end{array}$ & $\begin{array}{l}\text { Satisfaction } \\
\text { scores }\end{array}$ \\
\hline $18-40$ & 222 & $8.05 \pm 2.02$ & $9.66 \pm 1.05$ \\
$41-60$ & 184 & $7.77 \pm 2.03$ & $9.53 \pm 1.03$ \\
$61-83$ & 33 & $7.60 \pm 2.71$ & $9.39 \pm 1.14$ \\
\hline
\end{tabular}

Table 3 Preoperative symptoms and postoperative satisfaction according to sex

\begin{tabular}{llll}
\hline Sex & $\begin{array}{l}\text { Number } \\
\text { of patients } \\
(\mathbf{N}=\mathbf{5 0 0})\end{array}$ & $\begin{array}{l}\text { Symptoms } \\
\text { scores }\end{array}$ & $\begin{array}{l}\text { Satisfaction } \\
\text { scores }\end{array}$ \\
\hline Female & $24 \mathrm{I}$ & $8.56 \pm \mathrm{I} .55$ & $9.58 \pm \mathrm{I} .3 \mathrm{I}$ \\
& & $(95 \% \mathrm{Cl} 8.3-8.7)$ & $(95 \% \mathrm{Cl} 9.4-9.7)$ \\
Male & 259 & $7.23 \pm 2.36$ & $9.53 \pm \mathrm{I} .16$ \\
& & $(95 \% \mathrm{Cl} 6.9-7.5)$ & $(95 \% \mathrm{Cl} 9.3-9.7)$ \\
& & $P<0.0 \mathrm{I}$ & $P=0.6 \mathrm{I}$ \\
\hline
\end{tabular}

Regarding sex differences, women presented higher levels of symptoms score compared to men, but similar scores on postoperative satisfaction.

Although there are a large number of studies conducted to understand recurrence rates after pterygium surgery, there is a lack of portrayal about its impact on patients' quality of life, and mainly the subjective satisfaction related to the surgery procedure, hence the importance of the study and our interest in approaching the goal.
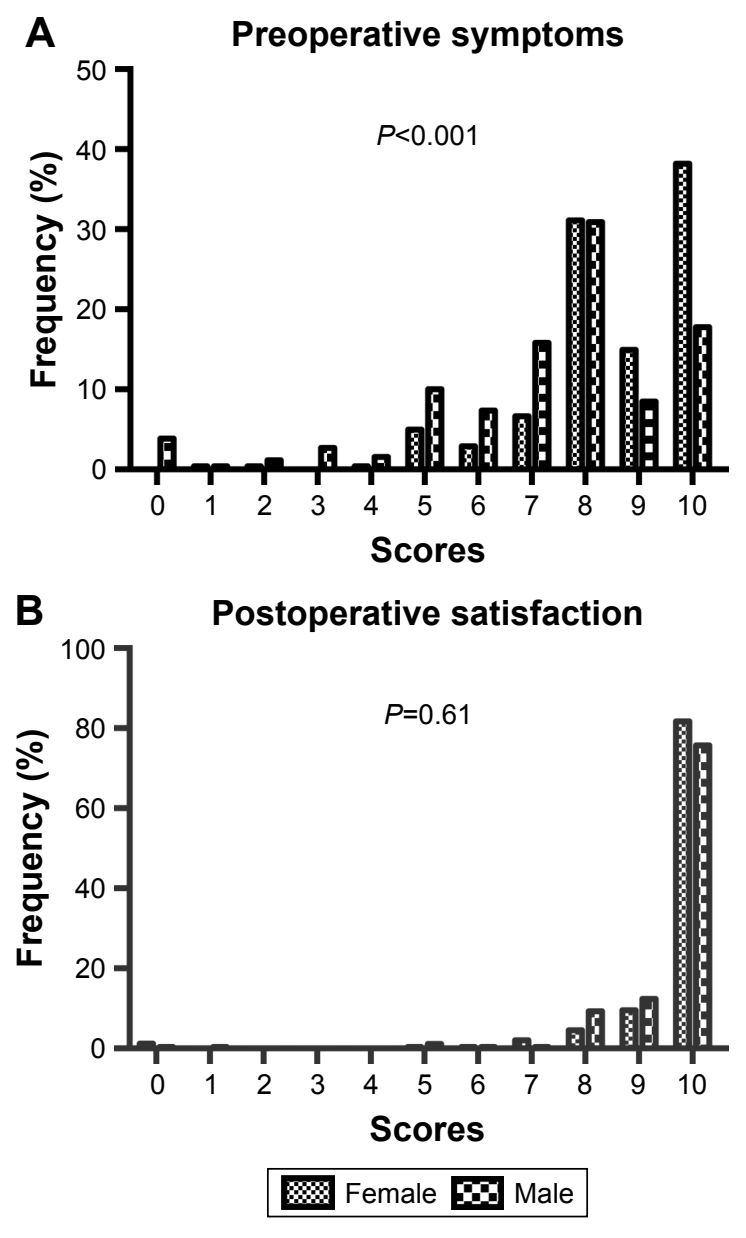

Figure 4 Preoperative symptoms (A) and postoperative satisfaction (B) according to sex. 


\section{Conclusion}

The present study shows that pterygium excision surgery using conjunctival autograft transplantation and fibrin glue improved quality of life related to pterygium symptoms for patients affected by the condition with high rates of satisfaction. However, there is still a lack of understanding on pterygium mechanisms, no consensus on best surgical technique and the recurrence rates remain a challenge, justifying the need for further research in this area.

\section{Acknowlegment}

FAPESP grant number 2014/19138-5 (Monica Alves, principal investigator and senior author).

\section{Disclosure}

The authors report no conflicts of interest in this work.

\section{References}

1. Bradley JC, Yang W, Bradley RH, Reid TW, Schwab IR. The science of pterygia. Br J Ophthalmol. 2010;94(7):815-820.

2. Ang M, Li X, Wong W, et al. Prevalence of and racial differences in pterygium: a multiethnic population study in Asians. Ophthalmology. 2012;119(8):1509-1515.

3. Shiroma H, Higa A, Sawaguchi S, et al. Prevalence and risk factors of pterygium in a southwestern island of Japan: the Kumejima Study. Am J Ophthalmol. 2009;148(5):766-771.e1.
4. Liu L, Wu J, Geng J, Yuan Z, Huang D. Geographical prevalence and risk factors for pterygium: a systematic review and meta-analysis. $B M J$ Open. 2013;3(11):e003787.

5. Hirst LW. The treatment of pterygium. Surv Ophthalmol. 2003;48(2): 145-180.

6. Akhter W, Tayyab A, Kausar A, Masrur A. Reducing postoperative pterygium recurrence: comparison of free conjunctival auto-graft and conjunctival rotation flap techniques. J Coll Physicians Surg Pak. 2014; 24(10):740-744.

7. Tsumi E, Levy J, Pitchkhadze A, Baidousi A, Lifshitz T. New approach for pterygium removal using 20\% ethanol. Int Ophthalmol. 2012; 32(5):443-448.

8. Altay Y, Balta Ö. Intraoperative application of 5-fluorouracil and mitomycin $\mathrm{C}$ as chemoadjuvants in primary pterygium surgery. Turk J Med Sci. 2016;46(2):321-327.

9. Luanratanakorn P, Ratanapakorn T, Suwan-Apichon O, Chuck RS. Randomised controlled study of conjunctival autograft versus amniotic membrane graft in pterygium excision. Br J Ophthalmol. 2006;90(12): 1476-1480.

10. Lan A, Xiao F, Wang Y, Luo Z, Cao Q. Efficacy of fibrin glue versus sutures for attaching conjunctival autografts in pterygium surgery: a systematic review with meta-analysis and trial sequential analysis of evidence. Oncotarget. 2017;8(25):41487-41497.

11. Karalezli A, Kucukerdonmez C, Akova YA, Altan-Yaycioglu R, Borazan M. Fibrin glue versus sutures for conjunctival autografting in pterygium surgery: a prospective comparative study. Br J Ophthalmol. 2008;92(9):1206-1210.

12. Alsmman AH, Radwan G, Abozaid MA, Mohammed UA, Abd Elhaleim NG. Preoperative subconjunctival combined injection of bevacizumab and mitomycin $\mathrm{C}$ before the surgical excision of primary pterygium: clinical and histological results. Clin Ophthalmol. 2017;11:493-501.
Clinical Ophthalmology

\section{Publish your work in this journal}

Clinical Ophthalmology is an international, peer-reviewed journal covering all subspecialties within ophthalmology. Key topics include: Optometry; Visual science; Pharmacology and drug therapy in eye diseases; Basic Sciences; Primary and Secondary eye care; Patient Safety and Quality of Care Improvements. This journal is indexed on

\section{Dovepress}

PubMed Central and CAS, and is the official journal of The Society of Clinical Ophthalmology (SCO). The manuscript management system is completely online and includes a very quick and fair peer-review system, which is all easy to use. Visit http://www.dovepress.com/ testimonials.php to read real quotes from published authors. 